\title{
Comparative Effects of Selected Underutilized Wild Beans on Plasma Lipid Profile and Liver Function of Rats Fed with High Fats Diet
}

\author{
0. A. Awoyinka1, T. R. Omodara ${ }^{2}$, F. C. Oladele1, D. D. Ajayi ${ }^{3}$, H. A. Babalola \\ B. A. Olofinbiyi ${ }^{5}$, G. S. Adeleye ${ }^{6}$, E. O. Odesanmi ${ }^{7}$ \\ ${ }^{1}$ Department of Medical Biochemistry, College of Medicine, Ekiti State University, Ado Ekiti, Nigeria
${ }^{2}$ Department of Microbiology, Faculty of Sciences, Ekiti State University, Ado Ekiti, Nigeria
${ }^{3}$ Department of Chemical Pathology, Ekiti State University Teaching Hospital, Ado Ekiti, Nigeria
${ }^{4}$ Department of Science Laboratory (Biochemistry Option), Ekiti State University, Ado Ekiti, Nigeria
${ }^{5}$ Department of Medicine, College of Medicine, Ekiti State University, Ado Ekiti, Nigeria
${ }^{6}$ Department of Physiology, Ekiti State University, Ado Ekiti, Nigeria
${ }^{7}$ Department of Biochemistry, Ekiti State University, Ado Ekiti, Nigeria
Email: olayinka.awoyinka@eksu.edu.ng
}

How to cite this paper: Awoyinka, O.A., Omodara, T.R., Oladele, F.C., Ajayi, D.D., Babalola, H.A., Olofinbiyi, B.A., Adeleye, G.S. and Odesanmi, E.O. (2019) Comparative Effects of Selected Underutilized Wild Beans on Plasma Lipid Profile and Liver Function of Rats Fed with High Fats Diet. Food and Nutrition Sciences, 10, 459-468. https://doi.org/10.4236/fns.2019.104034

Received: January 15, 2019

Accepted: April 23, 2019

Published: April 26, 2019

Copyright $\odot 2019$ by author(s) and Scientific Research Publishing Inc. This work is licensed under the Creative Commons Attribution International License (CC BY 4.0).

http://creativecommons.org/licenses/by/4.0/ (c) () Open Access

\begin{abstract}
Dietary fiber content of beans is known to be responsible in the management of metabolic syndrome by delaying the degree of glucose as fuels, changing fat utilization, and controlling appetite through increased satiety, thus lowering the risk of cardiovascular diseases. Hence some selected varieties of underutilized wild beans were evaluated to study their anti-lipidemic effects. Prior to this, attempts were made to ferment the non-digestible fractions of the beans with fermentable micro-organism and the respective gut metabolites were determined. Lipid profile result carried out in the blood showed high density lipoprotein to be significantly $(\mathrm{p} \leq 0.05)$ high in Pakala group with a value of $2.2 \pm 0.02$ compared to other groups. While for low density lipoprotein (LDL); rats with Otili in their diet had the highest LDL with a value of $0.45 \pm 0.01$. However, the group of rats fed with Feregede had the least cholesterol level compared to other groups of rats fed with respective wild beans and the negative control group. Otili had the highest ALP with value of $89 \pm 1.0$. Otili group also had a significant lower value of both aspartate amino transferase and alanine amino transferase. The biochemical indices reported in this study vary from one type of wild bean to another.
\end{abstract}

\section{Keywords}

Metabolic Syndrome, Dietary Fibres, Anti-Lipidemic, Alanine

Aminotransferase, Aspartate Aminotransferase 


\section{Introduction}

Metabolic syndrome is the group of metabolic conditions associated with the risks of cardiovascular diseases elevated serum triglycerides and LDL cholesterol, low HDL cholesterol, central adiposity, high serum glucose, and high blood pressure [1] [2]. Consumption of beans in the diet is considered beneficial for healthy individuals as well as those preconditioned for metabolic syndrome by lowering serum total cholesterol and LDL cholesterol [3] [4]. Resistant starch and dietary fiber content of beans are mainly responsible in the management of metabolic syndrome by delaying the degree of glucose as fuels, changing fat utilization, and controlling appetite through increased satiety, thus lowering the risk of cardiovascular diseases [5] [6].

Fermentation of soluble fiber (SF) as well as resistant starch (RS) by bacteria in the large intestine results in the generation of specific short chain fatty acids (SCFA), propionate being the dominant, which alters metabolic pathways resulting in reduced serum cholesterol [7] [8]. Thus, increased production of SCFA by fermentation of RS is an underlying reason for the protective benefits by the consumption of dry beans [7] [9]. The cholesterol lowering effect of dietary fiber has been ascribed to its ability to restrain the intestinal absorption of neutral steroids and bile acids and total steroid excretions [10]. Hypocholesterolemic effect can also be achieved by regular ingestion of beans that reduce the need to rely on animal proteins by replacing it through plant proteins [11]. In addition to this, beans $\alpha$-amylase inhibitor is known to have anti-obesity effect as $\alpha$-amylase inhibitory action to starch digestion causes energy restriction resulting in mobilization of body fat reserves [12].

Several epidemiological and clinical studies have shown positive effects of beans consumption in lowering the risk of coronary heart diseases and cardiovascular diseases [7] [13]. In an epidemiological trial, men and women consuming four times or more legumes per week decreased their risks of coronary heart diseases and cardiovascular diseases up to $22 \%$ and $11 \%$, respectively, as compared to those with once serving per week [14]. A $1 \%$ decline in serum total cholesterol reduces the risk of coronary heart disease by $2 \%$, while each $1 \%$ decline in serum LDL cholesterol decreases the risk to about $1 \%$ [15]. In a clinical trial, Anderson and Moore [16] investigated that utilization of $275 \mathrm{~g}$ of navy beans by hyper cholesterolemic patients for three weeks decreased serum cholesterol and LDL cholesterol up to $19 \%$ and $24 \%$, respectively; while in second trial, 24\% reduction was observed in both total cholesterol and LDL cholesterol under metabolic ward conditions with similar diet. Anderson [1] had previously also investigated that consumption of baked beans by hypercholesterolemic patients for two weeks reduced total cholesterol and LDL cholesterol by $12 \%$ and $15 \%$, respectively. Similarly, Han et al. [17] investigated that resistant starches of beans reduce the serum cholesterol concentration in rats. In another study, hyper cholesterolemic men were given half a cup daily intake of baked beans for a period of 8 weeks, which resulted in reductions of serum LDL cholesterol and 
total cholesterol by 5\% and 6\%, respectively [13]. Against this backdrop the mechanism of the prevention of the cardiovascular diseases by beans is well studied but not in the perspective of exploring the underutilized wild beans as presented in this study.

\section{Materials and Methods}

\subsection{Collection of Cultivar}

As described in our previous study [18] the legumes (beans) used in this work are of two types; Wild-type beans Sphenostyles stenocarp (Otili African yam bean), Cajanuscajan (Feregede Pigeon pea), Phaseolus lunatus (Pakala lima beans) and Edible bean Phaseolus vulgaris (Oloyin kidney bean). They are gotten from the farmers in Ado-Ekiti.

\subsection{Experimental Animals}

Twenty four albino rats were obtained from the college of medicine Animal house, Ekiti State University, Ado Ekiti, Ekiti state. Their weight ranged between 50 to 100 grams. The animals were acclimatized to the environment for 7 days. In feeding, the method of Shimin et al., [19] was adopted with slight modification. The rats were then randomly divided into five groups as shown in Table 1, (4 rats per group) according to average body weight, the groups were fed ad-libitum with a normal chow diet (NCD), a high dietary fiber diet (HD) containing $8 \%$ fiber supplement in total, a high-fat diet (HF) which provided $45 \%$ of its energy from fat, or a high-fat and dietary fiber diet (HFD). The main nutritional ingredients in the HD diets were adjusted to levels similar to those of the normal chow diet, and the main nutritional ingredients in the HFD diet were adjusted levels similar to those of the HF diet. The rats were observed every day and weighed every week and the food intakes were recorded for each group throughout the experiment.

\subsection{Dissection and Tissue Collection}

All of the rats were anesthetized with chloroform and venous blood was collected from the orbital vein for hematology and blood biochemical analyses. Then, the rats were killed via an aortic cut and immediately dissected. The liver was collected, frozen and stored at $-80^{\circ} \mathrm{C}$ for further analysis.

\subsection{Lipid Analysis}

\subsubsection{Preparation of Cholesterol Fraction}

Blood was collected in a tube with no anticoagulant and allowed to clot at room temperature for 30 minutes before centrifugation at $2500 \times \mathrm{g}$ for 20 minutes. The serum layer was removed and stored on ice. However, extra care was taken to avoid disturbing the white buffy layer and stored at $-80^{\circ} \mathrm{C}$ prior to performing the assay. Cholesterol level was assessed following Kit's manufacturer instruction (Randox, USA) on the aliquot samples. 
Table 1. Experimental design.

\begin{tabular}{ccc}
\hline$s / \mathbf{n}$ & Experimental group & Composition (100 grams) \\
\hline $\mathbf{1}$ & Basal/Positive Control & Chow \\
$\mathbf{2}$ & Negative Control & Chow + High Fat Diet \\
$\mathbf{3}$ & Feregede & Chow + HFD + Feregede \\
$\mathbf{4}$ & Otili & Chow + HFD + Otili \\
$\mathbf{5}$ & Pakala & Chow + HFD + Pakala \\
\hline
\end{tabular}

\subsubsection{Preparation of HDL Fractions}

Blood was collected with heparin or citrate to avoid hemolyzes and centrifuge at $2000 \times \mathrm{g}$ and $4^{\circ} \mathrm{C}$ for 10 minutes. The white buffy layer-plasma was gently removed and store on ice. Aliquot samples for testing and store. Dilutions in $1 \mathrm{X}$ assay were performed on aliquot samples after storage at $-80^{\circ} \mathrm{C}$. Thereafter, 200 $\mu \mathrm{L}$ of sample was added to $200 \mu \mathrm{L}$ of the precipitation Reagent (Randox, USA) and mixed well by vortexing. The mixture was allowed to incubate $5-10 \mathrm{mi}-$ nutes at room temperature before taking absorbance at $570 \mathrm{~nm}$.

\subsubsection{Preparation of LDL/VLDL Fraction}

Pellet obtained after removal of the HDL fraction was re-suspended and dissolved in $400 \mu \mathrm{L}$ of PBS and mixed well to obtain the LDL/VLDL fraction. Assay was carried out immediately by following Random Kit Manufacturer's instruction.

\subsubsection{Liver Function Analyses}

For the biochemical analyses, the blood samples were maintained $4^{\circ} \mathrm{C}$ for $2 \mathrm{~h}$ and then centrifuged at $3000 \mathrm{r} / \mathrm{min}$ for $20 \mathrm{~min}$ at $4^{\circ} \mathrm{C}$. The supernatant was stored at $-80^{\circ} \mathrm{C}$ total protein (TP), Alanine aminotransferase (ALT), aspartate aminotransferase (AST), and alkaline phosphatase (ALP), uric acid levels were analyzed following the commercial Random Kit (USA) and absorbance were measured using an automatic Biochemical Analyzer Camspec M106 Spectrophotometer (USA).

\section{Results and Discussion}

From this experimental rats model, the results of lipid profile as shown in Table 2 carried out on the blood of experimental animals showed high density lipoprotein (HDL) which is referred to as good cholesterol found to be highest in Pakala group with a value of $2.2 \pm 0.02$ while the positive control had the lowest HDL level with a value of $0.3 \pm 0.3$. HDL has several potential anti-atherogenic effects and protective effects on endothelial cells [20]. Therefore abnormal and reduced vaso-protective effects of HDL are closely associated with atherogenesis and an increased risk of cardiovascular disease. Oxidative modifications have been proposed for alteration and deterioration of HDL [21]. The oxidation of HDL particles is likely to have important consequences not only for cholesterol homeostasis in peripheral tissues but also for the development of vascular 
Table 2. Lipid profile in blood.

\begin{tabular}{cccc}
\hline GROUP & $\begin{array}{c}\text { High Density } \\
\text { Lipoprotein (HDL) }\end{array}$ & $\begin{array}{c}\text { Low Density } \\
\text { Lipoprotein (LDL) }\end{array}$ & Total Cholesterol (TC) \\
\hline 1 & $0.3 \pm 0.3$ & $0.35 \pm 0.01$ & $1.1 \pm 0.06$ \\
2 & $1.5 \pm 0.05$ & $0.02 \pm 0.02$ & $2.0 \pm 0.01$ \\
3 & $0.8 \pm 0.06$ & $0.35 \pm 0.07$ & $1.6 \pm 0.05$ \\
4 & $2.1 \pm 0.01$ & $0.45 \pm 0.01$ & $2.1 \pm 0.01$ \\
5 & $2.2 \pm 0.02$ & $0.4 \pm 0.02$ & $2.2 \pm 0.02$ \\
6 & $1.0 \pm 0.02$ & $0.4 \pm 0.01$ & $2.4 \pm 0.04$ \\
\hline
\end{tabular}

diseases associated with oxidative stress [20]. While for low density lipoprotein (LDL); rats laced with Otili in their diet had the highest LDL with a value of 0.45 \pm 0.01 , though not significantly different from other group fed with other wild underutilized beans. Interestingly the negative control significantly lower LDL compared to other groups with a value of $0.2 \pm 0.02$. LDL particles pose a risk for cardiovascular disease when they invade the endothelium and become oxidized, since the oxidized forms are more easily retained by the proteoglycans. A complex set of biochemical reactions regulates the oxidation of LDL particles, chiefly stimulated by presence of necrotic cell debris and free radicals in the endothelium. Increased concentration of LDL particles is strongly associated with the development of atherosclerosis over time [22]. However, the group of rats fed with Feregede had the least cholesterol level compared to other groups of rats fed with respective wild beans and the negative control group. The cholesterol level of other groups of rats fed with Otili and Pakala are not significantly different from each other and the negative control. High-density lipoprotein (HDL) is good cholesterol and low-density lipoprotein (LDL) is bad cholesterol. High cholesterol in serum is a leading risk factor for human cardiovascular disease such as coronary heart disease and stroke [23]. Against this backdrop it is suffice to declare that Feregede could have protection against heart diseases and other health challenges but the physical observations in the experiment would negate this assumption. The group fed with Feregede was less agile and sick compare to Otili and Pakala groups. The feeding pattern of each group shows that Otili group had more appetite for the feed and this is clearly seen in their body mass gain over the period of the experiment. There was a general similarity in the behaviour of the rats which have the wild beans in their feed. Unlike the controls and Otili other groups did not huddle together but lay separately, often on their backs with their limbs fully extended. The total protein present in Group 1 is higher with a value of $77 \pm 0.15$ compare to Group 2, 4, 6 and 5 with value of 75 $\pm 0.10,70 \pm 0.01,70 \pm 0.03$ and $69 \pm 0.01$ respectively while Group 3 had the lowest with a value of $59 \pm 0.04$, compared to the control. This indicates that many serve as a protective role against hyperlipidemia and hyperglycemia in rat fed with high fats diet [24] [25].

Alkaline phosphatases are classified as tissue-specific and tissue nonspecific types. Alkaline phosphatases found in the intestine, placenta, and germinal tis- 
sue are tissue-specific, which means they are found only in the tissues where they are expressed in physiological conditions but may contribute to the circulating pool of serum alkaline phosphatase under specific situations when there is increased stimulation of their production. The tissue-nonspecific alkaline phosphatase forms the majority of the fraction circulating in serum and therefore, is of clinical interest [26]. In this experimental analysis of the liver as shown in $\mathrm{Ta}$ ble 3, the lowest value of alkaline phosphatase (ALP) was found in positive control with the value $68 \pm 1.5$ and Otili had the highest ALP with value of $89 \pm 1.0$. Though the value obtained lies within the normal range [32], there is significant ( $p \leq 0.05)$ increase in the presence of alkaline phosphatase in other experimental groups. The principal clinical value of measuring serum alkaline phosphatase lies in the diagnosis of cholestatic liver disease. Some of the highest elevations in alkaline phosphatases are seen in patients with cholestasis. Usually, four-fold of the upper limit of normal or greater elevation is seen in up to $75 \%$ of the patients with cholestasis, either intrahepatic or extra hepatic [26].

AST is commonly measured clinically as a part of diagnostic liver function tests, to determine liver health. However, it is important to keep in mind that the source of AST (and, to a lesser extent, ALT) in blood tests may reflect pathology in organs other than the liver. Larry (21) submitted that when the AST is higher than ALT, a muscle source of these enzymes should be considered. For example, muscle inflammation due to dermatomyositis may cause AST > ALT. This is a good reminder that AST and ALT are not good measures of liver function because they do not reliably reflect the synthetic ability of the liver and they may come from tissues other than liver [27]. Compared to the control, the other groups were found to be lower in Aspartate Aminotransferase. Otili group had a significant lower value of $465 \pm 1.2$ compare to that of the control while the rest experimental group had an increased value of AST compared to the control. Similar result was also found in alanine amino transferase (ALT) where Otili group had lower ALT of $1710 \pm 4.2$ compare to other groups. Aspartate aminotransferase (AST) and alanine aminotransferase (ALT) are frequently used as markers of hepatocellular injury. AST is expressed in mitochondria of the liver and cytosol of red blood cells and muscles; thus it is not specific for liver injury [28]. Since ALT is less abundant outside of the liver, an increased ALT level is more suggestive of liver disease. Levels of both are markedly elevated ( $>5-$ to

Table 3. Liver function tests.

\begin{tabular}{cccc}
\hline GROUP & Alkaline Phosphatase & AST & ALT \\
\hline 1 & $68 \pm 1.5$ & $1080 \pm 2.5$ & $1980 \pm 1.2$ \\
2 & $82 \pm 1.2$ & $850 \pm 3.8$ & $2640 \pm 1.3$ \\
3 & $85 \pm 1.4$ & $712 \pm 3.4$ & $4635 \pm 1.2$ \\
4 & $89 \pm 1.0$ & $465 \pm 1.2$ & $1710 \pm 4.2$ \\
5 & $71 \pm 1.3$ & $1050 \pm 2.1$ & $3330 \pm 1.1$ \\
\hline
\end{tabular}


10-fold normal) with hepatocellular injury caused by hepatitis, hepatotoxicity, ischemia, genetic or metabolic liver disorders. Elevation of AST in excess of ALT suggests extra-hepatic source of injury. With acute biliary obstruction, there are initial sharp increases in ALT and AST levels and a rapid decline in 12 - 72 hours as obstruction is relieved. In chronic cholestasis, aminotransferases are usually only mildly elevated. With hepatocellular injury, ALT and AST levels tend to remain more significantly elevated longer. In acute liver failure a rapid decline in ALT and AST levels with worsening coagulopathy is a poor prognostic factor [29] [30] [31] [32].

Generally the pattern in liver protein in the experimental groups-Feregede, Otili and Pakala compare to the two controls may be ascribed to intake of the diet mixed with high fats. Total protein was found to be higher in the liver of the group fed with feregede with the value of $84 \pm 8.3$. Total protein was found to be higher in Group 3 with the value of $84 \pm 8.3$ compared to Group 1 having $15.4 \pm$ 0.04. Decreased in the control total protein may be as result of decreased synthetic capacity of the rats [33] [34]. It may be hoped that determinations of liver protein in varying metabolic states will be useful in trying to define the part played by the liver in the processes of protein metabolism. The effect on the blood tissue is in consonance with the view that all the differences are responses to change in functions [35].

\section{Conclusion}

In summary, dry beans played an important clinical role in the human nutrition with reduced risk of chronic disease and could be an exceptionally cost effectual approach for improving health. Rats fed with Otili (Sphenostyles stenocarpa) and Feregede (cajanus cajan) expressed higher resistibility ability in the induction of high fat diet but poor resistibility was exhibited or experienced in Pakala (Phaseolus lunatus) and edible bean.

\section{Acknowledgements}

The present project was partly funded by Tet Fund Individual Based Research grant 2017-2018 sessions. To embark on this study, the invaluable encouragement of Prof. (Mrs.) Rocio Campos-Vega of Autonomous University Queretaro, Mexico is highly acknowledged.

\section{Conflicts of Interest}

The authors declare no conflicts of interest regarding the publication of this paper.

\section{References}

[1] Anderson, J.W. (1985) Cholesterol Lowering Effects of Canned Beans for Hypercholesterolmic. Medical Clinical Resources, 33, 871-875.

[2] Duane, W.C. (1997) Effects of Legume Consumption on Serum Cholesterol, Biliary 
Lipids, and Sterol Metabolism in Humans. Journal of Lipid Research, 38, $1120-1128$.

[3] Seymour, G., Elliot, W., Christopher, K.Z., Regina, S. and George, J.K. (1987) Compensatory Enlargement of Human Atherosclerotic Coronary Arteries. The New England Journal of Medicine, 316, 1371-1375.

https://doi.org/10.1056/NEJM198705283162204

[4] Westerbacka, J., Lammi, K., Hakkinen, A.M., Rissanen, A., Salminen, I., Aro, A., et al. (2005) Dietary Fat Content Modifies Liver Fat in Overweight Nondiabetic Subjects. The Journal of Clinical Endocrinology and Metabolism, 90, 2804-2809. https://doi.org/10.1210/jc.2004-1983

[5] Duhan, A., Khetarpaul, N. and Bishnoi, S. (2001) Saponin Content and Trypsin Inhibitor Activity in Processed and Cooked Pigeon Pea Cultivar. International Journal of Food Science and Nutrition, 52, 53-59.

https://doi.org/10.1080/09637480020027200

[6] Campos-Vega, R., Reynoso-Camacho, R., Pedraza-Aboytes, G., Acosta-Gallegos, J.A., Maldonado, S.H.G., Paredes-Lopez, O., Oomah, B.D. and Loarca-Piña, G. (2009) Chemical Composition and in Vitro Polysaccharide Fermentation of Different Beans (Phaseolus vulgaris L.). Journal of Food Science, 74, T59.

https://doi.org/10.1111/j.1750-3841.2009.01292.x

[7] Finley, J.W., Burrell, J.B. and Reeves, P.G. (2007) Pinto Bean Consumption Changes SCFA Profiles in Fecal Fermentations, Bacterial Populations of the Lower Bowel, and Lipid Profiles in Blood of Humans. The Journal of Nutrition, 137, 2391-2398. https://doi.org/10.1093/jn/137.11.2391

[8] Hartley, L., May, M.D., Loveman, E., Colquitt, J.L. and Rees, K. (2016) Dietary Fibre for the Primary Prevention of Cardiovascular Disease. Cochrane Database Syst Rev., 1, Cd011472. https://doi.org/10.1002/14651858.CD011472.pub2

[9] Awoyinka, O.A., Omodara, T.R., Oladele1, F.C., Aina, O.O. and Ajayi, O.E (2018) In-Vitro Metabolite Colonic Production from Otili (Sphenostylis stenocarpa) as Influenced by Selected Gastrointestinal Microbes. Advances in Bioscience and Biotechnology, 9, 584-595. http://www.scirp.org/journal/abb

[10] Howarth, N., Saltzman, E. and Roberts, S. (2001) Dietary Fiber and Weight Regulation. Nutrition Reviews, 59, 129-139. https://doi.org/10.1111/j.1753-4887.2001.tb07001.x

[11] Gylling, H. and Miettinen, T.A. (2005) The Effect of Plant Stanol- and Sterol-Enriched Foods on Lipid Metabolism, Serum Lipids and Coronary Heart Disease. Annals of Clinical Biochemistry, 42, 254-263.

[12] Layer, P., Carlson, G.L. and Di Magno, E.P. (1985) Partially Purified White Bean Amylase Inhibitor Reduces Starch Digestion in Vitro and Inactivates Intraduodenal Amylase in Human. Gastroenterology, 88, 1895-1902. https://doi.org/10.1016/0016-5085(85)90016-2

[13] Hutchins, A., Winhan, D.M. and Thompson, S.V. (2012) Phaseolus Beans: Impact on Glycaemic Response and Chronic Disease Risk in Human Subjects. British Journal of Nutrition, 108, S52-S65. https://doi.org/10.1017/S0007114512000761

[14] Hu, F.B. (2003) Plant-Based Foods and Prevention of Cardiovascular Disease: An Overview. American Journal of Clinical Nutrition, 78, 544S-551S. https://doi.org/10.1093/ajcn/78.3.544S

[15] Jacobs, D.R. and Gallaher, D.D. (2004) Whole Grain Intake and Cardiovascular Disease: A Review. Current Atherosclerosis Reports, 6, 415-423.

https://doi.org/10.1007/s11883-004-0081-y 
[16] Anderson, G.H. and Moore, S.E. (2004) Dietary Proteins in the Regulation of Food Intake and Body Weight in Humans. Journal of Nutrition, 134, 974-979.

[17] Han, K., Fukushima, M. and Shimizu, K. (2003) Resistant Starches of Beans Reduce the Serum Cholesterol Concentration in Rats. Journal of Nutritional Science and Vitaminology, 49, 281-286.

[18] Awoyinka, O.A., Omodara, T.R., Oladele, F.C., Aina, O.O. and Akinluyi, O. (2018) In-Vitro Measurement of $\mathrm{pH}$ and Antioxidant Capacity during Colonic Fermentation of Selected Underutilized Wild and Edible Beans. Advances in Microbiology, 8 , 965-974. https://doi.org/10.4236/aim.2018.812065

[19] Shimin, C., Xingtian, C., Mingzhang, G., Yiling, T., Wentao, X., Kunlun, H. and Yuxing, Z. (2017) Insoluble Dietary Fiber from Pear Pomace Can Prevent High-Fat Diet-Induced Obesity in Rats Mainly by Improving the Structure of the Gut Microbiota. Journal of Microbiology and Biotechnolog, 27, 856-867.

https://doi.org/10.4014/jmb.1610.10058

[20] Hirokazu, H. (2017) Degenerated HDL and Its Clinical Implications. In: Komoda, T., Ed., The HDL Handbook: Biological Functions and Clinical Implications, 3rd Edition, Elsevier, UK, 37-63.

[21] Larry, R.E. (2015) Hyperlipidemias. In: Engelking, L., Eds., Textbook of Veterinary Physiological Chemistry, Academic Press, Cambridge, 427-433.

https://www.sciencedirect.com/topics/biochemistry-genetics-and-molecular-biolog y/hyperlipidemia

[22] Pittaway, J.K., Ahuja, K.D., Cehun, M., Chronopoulos, A., Robertson, I.K. and Nestel, P.J. (2006) Dietary Supplementation with Chickpeas for at Least 5 Weeks Results in Small but Significant Reductions in Serum Total and Low-Density Lipoprotein Cholesterols in Adult Woman and Men. Annals of Nutrition and Metabolism, 50, 512-518. https://doi.org/10.1159/000098143

[23] O'Hare, E.A. (2014) Disruption of Ldlr Causes Increased LDL-c and Vascular Lipid Accumulation in a Zebrafish Model of Hypercholesterolemia. Journal of Lipid Research, 55, 2242-2253. https://doi.org/10.1194/jlr.M046540

[24] Grant, G., Dorward, P.M., Buchan, W.C., Armour, J.C. and Pusztai, A. (1995) Consumption of Diets Containing Soya Beans (Glycine max), Kidney Beans (Phaseolus vulgaris), Cowpeas (Vigna unguiculata) or Lupin Seeds (Lupinus augustifolius) by Rats for Up to 700 Days: Effects on Body Composition and Organ Weights. British Journal of Nutrition, 73, 17-29. https://doi.org/10.1079/BJN19950005

[25] Jang, H. (2017) The Herbal Formula KH-204 Is Protective against Erectile Dysfunction by Minimizing Oxidative Stress and Improving Lipid Profiles in a Rat Model of Erectile Dysfunction Induced by Hypercholesterolaemia. BMC Complementary and Alternative Medicine, 17, Article ID: 1817. https://doi.org/10.1186/s12906-017-1588-4

[26] Dhruv, L. and Savio, J. (2018) Alkaline Phosphatase. StatPearls Publishing, Treasure Island. https://www.ncbi.nlm.nih.gov/books/NBK459201/

[27] Shi, J., Arunasalam, K., Yeung, D., Kakuda, Y., Mittal, G. and Jiang, Y. (2004) Saponins from Edible Legumes: Chemistry, Processing, and Health Benefits. Journal of Medicinal Food, 7, 67-78. https://doi.org/10.1089/109662004322984734

[28] Hirotsu, K., Goto, M., Okamoto, A. and Miyahara, I. (2005) Dual Substrate Recognition of Aminotransferases. The Chemical Record, 5, 160-172.

https://doi.org/10.1002/tcr.20042

[29] Anahat, D.M.D., Randolph, H. and Steadman, M.D. (2012) Liver Diseases. In: Fleisher, L., Ed., Anesthesia and Uncommon Diseases, 6th Edition, Science Direct, 
UK, $162-214$.

[30] Pusztai, A., Grant, G., Duguid, T., Brown, D.S., Peumans, W.J. and Van Damme, E.J. (1995) Inhibition of Starch Digestion by $\alpha$-Amylase Inhibitor Reduces the Efficiency of Utilization of Dietary Proteins and Lipids and Retards the Growth of Rats. Journal of Nutrition, 125, 1554-1562.

[31] Kochhar, S. and Christen, P. (1992) Mechanism of Racemization of Amino Acids by Aspartate Aminotransferase. European Journal of Biochemistry, 203, 563-569. https://doi.org/10.1111/j.1432-1033.1992.tb16584.x

[32] Singh, B.B., Ehlers, J.D., Sharma, B. and Freire, F.R. (2009) Recent Progress in Beijing, China. License Number SCXK, Beijing, 15.

[33] Belitz, H.D. and Weder, J.K.P. (1990) Protein Inhibitors of Hydrolases in Plants Foodstuffs. Food Reviews International, 6, 151-211. https://doi.org/10.1080/87559129009540866

[34] Cassidy, A., Albertazzi, P., Lise, I., Nielsen, W., Hall, G., Williamson, I. and Tetens. (2006) Critical Review of Health Effects of Soyabean Phyto-Oestrogens in Post-Menopausal Women. The Proceedings of the Nutrition Society, 65, 76-92. https://doi.org/10.1079/PNS2005476

[35] Ryan, E., Galvin, K., O’Connor, T.P., Maguire, A.R. and O’Brien, N.M. (2007) Phytosterol, Squalene, Tocopherol Content and Fatty Acid Profile of Selected Seeds, Grains, and Legumes. Plant Foods for Human Nutrition, 62, 85-91.

https://doi.org/10.1007/s11130-007-0046-8 